\title{
Squalamine and age-related macular degeneration. Did the Shark lose its teeth?
}

\author{
Ayseguel Tura, Mahdy Ranjbar, Swaantje Grisanti and Salvatore Grisanti* \\ Department of Ophthalmology, University-Hospital Schleswig-Holstein, University of Luebeck, Luebeck, Germany
}

\begin{abstract}
Squalamine is a steroid-polyamine conjugate compound with anti-angiogenic activity. Based on scientific ground work, it started its journey as a potential drug to treat several pathologies including age-related macular degeneration in the mid-1990s. After an odyssey of more than 20 years and clinical trials for neovascular macular degeneration with both systemic and topical application of the compound, by not succeeding in the Phase III trials as of 2018, this journey seems to have reached an end.
\end{abstract}

\section{Introduction}

Squalamine was originally developed by Magainin Pharmaceuticals (subsequently called Genaera), in the mid-1990s based on the work of researcher Michael Zasloff. It is an antiangiogenic natural cationic steroid that has been isolated from tissues of several species of dogfish shark (Squalus acanthias). Squalamine was later owned by Genaera Corp., which closed, and the rights were sold by its liquidator to Ohr Pharmaceutical in 2009. The compound was studied as a potential anti-angiogenic drug, then tested in clinical studies for several types of cancer and received FDA fast track status for the treatment of "wet" age-related macular degeneration (AMD). Though squalamine may have a potential in the treatment of other processes, e.g. infections, this review will primarily focus on its anti-angiogenic capacity that is the present target in treating AMD.

\section{Molecule}

Squalamine, a steroid-polyamine conjugate, was first discovered in the tissues of the dogfish shark (Squalus acanthias) and recognized as a broad-spectrum anti-microbial agent in 1993[1,2]. Thereafter it was also identified within the circulating white blood cells of the sea lamprey (Petromyzon marinus) [3]. The chemical structure of squalamine (3ß-N1-N-[3-(4-aminobutyl)]-1,3-diaminopropane)-7a, 24R-dihydroxy$5 a$-cholestane 24 sulfate; molecular weight $=628$ ) (Figure 1 ) was determined by fast atom bombardment mass spectroscopy and nuclear magnetic resonance. Squalamine was further characterized as a cationic steroid [4]. Since only trace amounts of squalamine are present in the liver of the shark, obtaining large amounts of the steroidal molecule from its natural source is difficult. Subsequently methods to make it synthetically have been developed [5-7]. The molecule carries a net positive charge by virtue of its spermidine moiety and exhibits a high affinity for anionic phospholipids $[8,9]$. This may be a major reason for its potent bactericidal activity against both gram-negative and grampositive bacteria. Furthermore, it is fungicidal, virucidal, and induces osmotic lysis of protozoa $[10,11]$. On the other hand, it was also found to have pharmacological activity in endothelial cells, inhibiting several growth factor-dependent processes (such as angiogenesis, migration as well as proliferation) both in vitro and in vivo [12-18].<smiles>CC(C)C(CC[C@@H](C)[C@H]1CC[C@H]2[C@H]3[C@H](CC[C@@]21C)[C@@]1(C)CCC(NCCCNCCCCN)C[C@@H]1C[C@H]3O)OS(=O)(=O)O</smiles>

\section{Action mode}

Recently, squalamine was discovered to enter cells and cause displacement of proteins that are associated through electrostatic interactions with the inner face of the cytoplasmic membrane [19-21]. Due to its positive charge, on entry into a eukaryotic cell, it neutralizes the negative charge of the surface to which it binds [20]. Surprisingly, this disruption of electrostatic potential can occur without obvious structural damage to the cell membrane as measured by changes in permeability [20]. After entering a cell, squalamine subsequently persists and then exits over the course of hours [22-24]. Activated endothelial cells have been described to intake the drug through structures known as caveolae, which are small invaginations in the cellular membrane. Once it is taken up by the cell, it binds to calmodulin, preventing downstream signaling of the pro-angiogenic factors $[25,26]$.

*Correspondence to: Salvatore Grisanti, Department of Ophthalmology, UKSH, University of Luebeck Ratzeburger Allee 160, D-23538 Luebeck, Germany, Tel: +4950043901; Fax: +4950043904; E-mail: salvatore.grisanti@uksh.de

Key words: squalamine, VEGF-inhibition, age-related macular degeneration, angiogenesis

Received: November 30, 2018; Accepted: December 10, 2018; Published: December 14, 2018 
Intracellularly, squalamine exerts downstream antiangiogenic effects based on a novel intracellular mechanism of action. It has the ability to inhibit several growth factors such as vascular endothelial growth factor (VEGF), basic fibroblast growth factor (bFGF), and platelet-derived growth factor (PDGF). It may also interact with other signaling pathways.

Squalamine interrupts and reverses multiple facets of the angiogenic process. It additionally inhibits integrin expression and reverses cytoskeletal formation, thereby resulting in endothelial cell inactivation and apoptosis. It specifically inhibits brush-border $\mathrm{Na}^{+} / \mathrm{H}^{+}$exchanger isoform NHE3, a sodium-hydrogen exchanger present on cell surfaces that regulates intracellular $\mathrm{pH}$ and is also known to regulate endothelial cell volume and shape. Growth factor related stimulation of the VEGF receptors (VEGFR) activates the MAP kinase pathways involved in blood vessel growth. Inhibition of the sodium-proton exchanger leads to changes in intracellular $\mathrm{pH}$ and subsequent inhibition of MAP kinase activity.

\section{Experimental studies}

The anti-angiogenic effect of squalamine was proven in different experimental models of neovascularization. Using a primate model, Genaidy et al. demonstrated in 2002 that systemic squalamine injection inhibited the development of iris neovascularization and caused partial regression of the pathological vessels. Interestingly, intravitreally injected squalamine did not affect the development of the pathological vessels [16].

Systemically administered squalamine lactate was also able to partially reduce choroidal neovascular membrane development induced by laser trauma in a rat model [27].

Squalamine was also shown to be a very active inhibitor of oxygeninduced retinopathy (OIR) in mouse neonates at doses as low as $1 \mathrm{mg} /$ $\mathrm{kg}$ given once subcutaneously. Further, squalamine given late in the course of OIR improved retinopathy by inducing regression of retinal neovessels and abrogating invasion of new vessels beyond the innerlimiting membrane of the retina $[14,28]$.

In 2012, Ohr Pharmaceutical announced and presented a poster entitled "A Novel Eye Drop Formulation of Squalamine For Exudative AMD: evaluation of ocular distribution and ocular safety in rabbits" at the Association for Research in Vision and Ophthalmology (ARVO) Annual Meeting. The company presented data on the ocular tissue uptake and biodistribution of squalamine eye drops in Dutch belted rabbits when administered once or twice daily in each eye for up to fourteen days. Squalamine concentrations in the posterior sclera/ choroid tissues were well above the previously suggested target therapeutic levels and sustained above that level for a full dosing interval. Moreover, the eye drop was found to be safe to ocular tissues, consistent with previous longer-term studies. The results indicated a rapid uptake to the posterior sclera/choroid ocular tissues with slow tissue clearance and sustained concentrations well above threshold antiangiogenic levels, which persist throughout the period in between doses ("trough level"). Safety to ocular tissues with no signs of ocular adverse clinical findings were consistent with previous longer-term toxicity studies. The systemic uptake was negligible which therefore minimizes the risk for systemic adverse events [29].

\section{Clinical trials}

After having been tested in an exudative AMD phase I study, the absence of any safety concerns led to several phase II trials [30-32].
Patients received a squalamine infusion once a week for 4 weeks. The high dose group ( $40 \mathrm{mg} /$ infusion) lead to a mean change in BCVA (best-corrected visual acuity) of +3.8 letters after the second dose and + 5.8 letters 1 week after the final dose. Adding to the positive biological effect with improvement or stability in the study eye of those patients receiving higher doses of the drug, the fellow non-study eyes with advanced macular degeneration also showed significant improvement after drug administration. However, because of pharmacokinetic issues of the intravenous delivery and local infusion site reactions, this route of medication was discontinued [33].

As a consequence of this result, a Phase 2 (IMPACT) study with a topical eye drop formulation (squalamine lactate ophthalmic solution $0.2 \%)$ was initiated [34].

The IMPACT trial was a phase II prospective, randomized, doublemasked, placebo-controlled, multicenter, interventional study designed to evaluate the safety and efficacy of a topical $0.2 \%$ ophthalmic formulation of squalamine in patients with neovascular AMD. A total of 142 patients were enrolled who were treatment naive with AMDrelated choroidal neovascularization with size 12-disc diameters or less and BCVA of 20/40 to 20/320. All patients received ranibizumab at baseline and were then randomized in a 1:1 ratio to receive either topical squalamine $0.2 \%$ or placebo drops twice a day. They were followed up monthly with PRN monthly ranibizumab treatments if intraretinal edema or subretinal fluid were noted. The IMPACT study showed that visual acuity gains were related to the size and type of lesions in this study population. A positive benefit in terms of visual acuity outcomes was shown in patients whose lesions had a classic component. Further analysis of lesion type to predict visual acuity gains demonstrated that the smaller the occult CNV size, the greater the effect on visual acuity, with or without classic component. Those patients treated with ranibizumab monotherapy did not show a similar lesion-size dependent effect [35].

In conclusion, the IMPACT trial raised hopes that squalamine could be effective in achieving additional visual gains when used as a topical supplement to anti-VEGF injections. Therefore, the latest effort, the phase 3, MAKO trial for wet AMD was started [36].

The MAKO Study was a multicenter, randomized, double-masked, placebo-controlled clinical trial to evaluate the efficacy and safety of squalamine combination therapy for the treatment of wet AMD. Subjects were randomized 1:1 to receive topical squalamine lactate ophthalmic solution, $0.2 \%$, twice daily and monthly ranibizumab injections or topical placebo twice daily and monthly ranibizumab injections. Eligibility criteria for the study eye included new diagnosed neovascular AMD and no previous treatment, occult neovascularization, if present, measuring less than $10 \mathrm{~mm}$ as assessed by fluorescein angiography, and visual acuity between 20/40 and 20/320. A total of 237 subjects were randomized. Visual acuity was measured monthly using the Early Treatment of Diabetic Retinopathy Study (ETDRS) eye chart. The primary efficacy endpoint was the mean visual acuity gain at 9 months using a mixed-effects model for repeated measures (MMRM) analysis. Despite the fact that Ohr had used its phase 2 IMPACT trial to select the patient types most likely to benefit from its therapy, at 9 months, patients on ranibizumab monotherapy achieved a mean gain of 10.58 letters compared to a mean gain of 8.33 letters in the combination group.

\section{Conclusion}

Over the past decade, the only effective treatments that prevented vision loss in most patients with AMD were anti-VEGF agents [37,38]. 
Different strategies and treatment regimens tried to balance injections and visits to lower the burden for patients, caregivers, and the health system. But there are still several unmet demands that need to be covered and ophthalmology is at a turning point in the management of this disease. New drug delivery strategies and new ways of interfering with the involved molecular cascades of the disease rise hopes. Squalamine, is or was a compound that carried such a promise and hope over a very long time. It was studied in an eye drop formulation as a potential way to reduce the burden of intravitreal injections [24]. A Phase II trial failed in 2015, but a subpopulation with choroidal neovascularization apparently responded well enough to justify a Phase III trial. The MAKO study, however, erased this last glimpse of hope.

The aminosterol antiangiogenic squalamine, naturally occurring and synthesized from the liver of the dogfish shark, a promising molecule, suggested for the treatment of various diseases (including lung cancer and foot ulcers), with studies undertaken by 3 different companies, may have finally run out of chances. Which is the remaining perspective for squalamine? Focusing on "strategic alternatives to maximize shareholder value" is the financial vision of this story. The mere scientific vision would be to get back to the roots, thrive for a better understanding of the original molecule itself and of its way of action and the various influencing factors that may have jeopardized its effect in humans.

\section{References}

1. Moore KS, Wehrli S, Roder H, Rogers M, Forrest JN Jr, et al. (1993) Squalamine: an aminosterol antibiotic from the shark. Proc Natl Acad Sci U S A 90: 1354-1358. [Crossref]

2. Wehrli SL, Moore KS, Roder H, Durell S, Zasloff M (1993) Structure of the novel steroidal antibiotic squalamine determined by two-dimensional NMR spectroscopy. Steroids 58:370-378. [Crossref]

3. Yun SS1, Li W (2007) Identification of squalamine in the plasma membrane of white blood cells in the sea lamprey, Petromyzon marinus. J Lipid Res 48: 2579-2586. [Crossref]

4. Jones SR, Kinney WA, Zhang X, Jones LM, Selinsky BS (1996) The synthesis and characterization of analogs of the antimicrobial compound squalamine: 6 beta-hydroxy3-aminosterols synthesized from hyodeoxycholic acid. Steroids 61: 565-571. [Crossref]

5. Moriarty RM, Tuladhar SM, Guo L, Wehrli S (1994) Synthesis of squalamine. A steroidal antibiotic from the shark. Tetrahedron Lett 35: 8103-8106.

6. Moriarty RM, Enache LA, Kinney WA, Allan CS, Canary JW, et al. (1995) Stereoselective synthesis of squalamine from microbial metabolite. Tetrahedron Lett 36: $5139-5142$.

7. Brycki B, Koenig H, Pospieszny T (2015) Quaternary Alkylammonium Conjugates of Steroids: Synthesis, Molecular Structure, and Biological Studies. Molecules 20: 20887-20900.

8. Selinsky BS, Zhou Z, Fojtik KG, Jones SR, Dollahon NR, et al. (1998) The aminosterol antibiotic squalamine permeabilizes large unilamellar phospholipid vesicles. Biochim Biophys Acta 1370: 218-234. [Crossref]

9. Selinsky BS, Smith R, Frangiosi A, Vonbaur B, Pedersen L (2000) Squalamine is not a proton ionophore. Biochim Biophys Acta 1464: 135-141. [Crossref]

10. Alhanout K, Rolain JM, Brunel JM (2010) Squalamine as an example of a new potent antimicrobial agents class: a critical review. Curr Med Chem 17: 3909-3917. [Crossref]

11. Zasloff M, Adams AP, Beckerman B, Campbell A, Han Z, et al. (2011) Squalamine as a broad-spectrum systemic antiviral agent with therapeutic potential. Proc Natl Acad Sci US A 108: 15978-15983. [Crossref]

12. Sills AK Jr, Williams JI, Tyler BM, Epstein DS, Sipos EP, et al. (1998) Squalamine inhibits angiogenesis and solid tumor growth in vivo and perturbs embryonic vasculature. Cancer Res 58: 2784-2792. [Crossref]
13. Schiller JH, Bittner G (1999) Potentiation of platinum antitumor effects in human lung tumor xenografts by the angiogenesis inhibitor squalamine: Effects on tumor neovascularization. Clin Cancer Res 5: 4287-4294. [Crossref]

14. Higgins RD, Sanders RJ, Yan Y, Zasloff M, Williams JI (2000) Squalamine improves retinal neovascularization. Invest Ophthalmol Vis Sci 41:1507-1512. [Crossref]

15. Williams JI, Weitman S, Gonzalez CM, Jundt CH, Marty J, et al. (2001) Squalamine treatment of human tumors in nu/nu mice enhances platinum-based chemotherapies. Clin Cancer Res 7: 724-733. [Crossref]

16. Genaidy M, Kazi AA, Peyman GA, Passos-Machado E, Farahat HG, et al. (2002) Effect of squalamine on iris neovascularization in monkeys. Retina 22: 772-778. [Crossref]

17. Li D, Williams JI, Pietras RJ (2002) Squalamine and cisplatin block angiogenesis and growth of human ovarian cancer cells with or without HER-2 gene overexpression. Oncogene 21: 2805-2814. [Crossref]

18. Yin M, Gentili C, Koyama E, Zasloff M, Pacifici M (2002) Antiangiogenic treatmen delays chondrocyte maturation and bone formation during limb skeletogenesis. J Bone Miner Res 17: 56-65. [Crossref]

19. Yeung T, Gilbert GE, Shi J, Silvius J, Kapus A (2008) Membrane phosphatidylserine regulates surface charge and protein localization. Science 319: 210-213. [Crossref]

20. Sumioka A, Yan D, Tomita S (2010) TARP phosphorylation regulates synaptic AMPA receptors through lipid bilayers. Neuron 66: 755-767. [Crossref]

21. Alexander RT, Jaumouillé V, Yeung T, Furuya W, Peltekova I, et al. (2011) Membrane surface charge dictates the structure and function of the epithelial $\mathrm{Na}+\mathrm{H}+$ exchanger. EMBO J 30: 679-691. [Crossref]

22. Bhargava P, Marshall JL, Dahut W, Rizvi N, Trocky N, et al. (2001) A phase I and pharmacokinetic study of squalamine, a novel antiangiogenic agent, in patients with advanced cancers. Clin Cancer Res 7: 3912-3919. [Crossref]

23. Hao D, Hammond LA, Eckhardt SG, Patnaik A, Takimoto CH, et al. (2003) A Phase I and pharmacokinetic study of squalamine, an aminosterol angiogenesis inhibitor. Clin Cancer Res 9: 2465-2471. [Crossref]

24. Herbst RS, Hammond LA, Carbone DP, Tran HT, Holroyd KJ, et al. (2003) A phase I/IIA trial of continuous five-day infusion of squalamine lactate (MSI-1256F) plus carboplatin and paclitaxel in patients with advanced non-small cell lung cancer. Clin Cancer Res 9: 4108-4115. [Crossref]

25. Connolly B, Desai A, Garcia CA, Thomas E, Gast MJ (2006) Squalamine lactate for exudative age-related macular degeneration. Ophthalmol Clin North Am 9: 381-391. [Crossref]

26. Schlottmann PG, Alezzandrini AA, Zas M, Rodriguez FJ, Luna JD, et al. (2017) New Treatment Modalities for Neovascular Age-Related Macular Degeneration. Asia Pac J Ophthalmol (Phila) 6: 514-519. [Crossref]

27. Ciulla TA, Criswell MH, Danis RP, Williams JI, McLane MP, et al. (2003) Squalamine lactate reduces choroidal neovascularization in a laser-injury model in the rat. Retina 23 : 808-814. [Crossref]

28. Higgins RD, Yan Y, Geng Y, Zasloff M, Williams JI (2004) Regression of retinopathy by squalamine in a mouse model. Pediatr Res 56: 144-149. [Crossref]

29. Ohr Pharmaceutical Inc (2012) A Novel Eye Drop Formulation of Squalamine For Exudative AMD: evaluation of ocular distribution and ocular safety in rabbits. Annual Meeting of the Association for Research in Vision and Ophthalmology.

30. Garcia CA, Quiroz-Mercado H, Uwaydat S, Sepulveda-Flores R, Meza-de Regil A, et al. (2004) A Phase I/II Trial of Intravenous Squalamine Lactate for Treatment of Choroidal Neovascularization in Age Related Macular Degeneration (ARMD). Invest Ophthalmol Vis Sci 45: 2362.

31. Garcia CA, Connolly B, Thomas E, Levitt R, Desai A, et al. (2005) A Phase 2 MultiDose Pharmacokinetic Study of MSI-1256F (Squalamine Lactate) for the Treatment of Subfoveal Choroidal Neovascularization Associated with Age-Related Macular Degeneration (AMD). Invest Ophthalmol Vis Sci 46: 206.

32. Ciulla TA, Regillo C, Desai A, Levitt R, Nau J, et al. (2005) A Phase II, Multi-Center, Randomized, Controlled, Masked Study of the Effects of Squalamine Lactate in Combination with Visudyne $\mathbb{R}$ in Patients with Subfoveal Choroidal Neovascularization Associated with Age-Related Macular Degeneration. Invest Ophthalmol Vis Sci 46: 2363.

33. Bhagat N, Zarbin M (2015) Recent Innovations in Medical and Surgical Retina. Asia Pac J Ophthalmol (Phila) 4: 171-179. [Crossref] 
34. Ohr Pharmaceutical Inc (2017) Efficacy and Safety Study of Squalamine Ophthalmic Solution in Subjects with Neovascular AMD (IMPACT) study. Available at: https:/ clinicaltrials.gov/ct2/show/ NCT01678963.

35. Stoller GL, Ciulla TA, Elman M (2014) Interim Results from a Phase 2 Study of Squalamine Lactate Ophthalmic Solution $0.2 \%$ In the Treatment of Neovascular AgeRelated Macular Degeneration (AMD). Philadelphia: Paper presentation at the Retina Society; http://www.retinasociety.org/files/Retina_2014_Program: corrected pagescover_web.pdf; pg 103 of the program.
36. Ohr Pharmaceutical Inc (2018) Efficacy and Safety Study of Squalamine Ophthalmic Solution in Subjects with Neovascular AMD (MAKO) study. Available at: https:// clinicaltrials.gov/ct2/show/NCT02727881. NLM identifier: NCT02727881.

37. CATT Research Group, Martin DF, Maguire MG, Ying GS, Grunwald JE, et al. (2011) Ranibizumab and bevacizumab for neovascular age-related macular degeneration. $N$ Engl J Med 364: 1897-1908. [Crossref]

38. Falavarjani KG, Sadda SR (2017) Hot Topics in Pharmacotherapy for Neovascular Age-Related Macular Degeneration. Curr Pharm Des 23: 535-541. [Crossref]

Copyright: (C2018 Tura A. This is an open-access article distributed under the terms of the Creative Commons Attribution License, which permits unrestricted use, distribution, and reproduction in any medium, provided the original author and source are credited. 